\title{
Spotlight
}

\section{Optimizing Patient Care and Research: The Amsterdam Dementia Cohort}

\author{
Wiesje M. van der Flier ${ }^{\mathrm{a}, \mathrm{b}}$, Yolande A.L. Pijnenburg ${ }^{\mathrm{a}}$, Niels Prins ${ }^{\mathrm{a}}$, Afina W. Lemstra ${ }^{\mathrm{a}}$, \\ Femke H. Bouwman ${ }^{\mathrm{a}}$, Charlotte E. Teunissen ${ }^{\mathrm{c}}$, Bart N.M. van Berckel ${ }^{\mathrm{d}}$, Cornelis J. Stam ${ }^{\mathrm{e}}$, \\ Frederik Barkhof $^{\mathrm{d}}$, Pieter Jelle Visser ${ }^{\mathrm{a}}$, Evan van Egmond ${ }^{\mathrm{a}}$ and Philip Scheltens ${ }^{\mathrm{a}, *}$ \\ ${ }^{\mathrm{a}}$ Alzheimer Center, Department of Neurology, VU University Medical Center, Neuroscience Campus Amsterdam, \\ Amsterdam, The Netherlands \\ ${ }^{\mathrm{b}}$ Department of Epidemiology \& Biostatistics, VU University Medical Center, Neuroscience Campus Amsterdam, \\ Amsterdam, The Netherlands \\ ${ }^{\mathrm{c}}$ Department of Clinical Chemistry, VU University Medical Center, Neuroscience Campus Amsterdam, Amsterdam, \\ The Netherlands \\ ${ }^{\mathrm{d}}$ Department of Radiology \& Nuclear Medicine, VU University Medical Center, Neuroscience Campus Amsterdam, \\ Amsterdam, The Netherlands \\ ${ }^{\mathrm{e}}$ Department of Clinical Neurophysiology, VU University Medical Center, Amsterdam, The Netherlands
}

Accepted 21 January 2014

\begin{abstract}
Since its opening in 2000, patient care and research go hand in hand at the Alzheimer center of the VU University Medical Center, both organized in such a way that they mutually strengthen each other. Our mission is to give patients a voice by lifting the stigma on dementia, to find new diagnostic and treatment strategies, and, ultimately, to cure diseases that cause dementia. Our healthcare pathway is uniquely designed to accommodate all necessary investigations for the diagnostic work-up of dementia in one day (one-stop shop). A second unique feature is that research has been fully integrated in the healthcare pathway. The resulting Amsterdam Dementia Cohort now includes over 4000 patients, and for the majority of these, we have MRI, EEG, blood (serum, plasma), DNA, and CSF available. The Amsterdam Dementia Cohort forms the basis of much of our research, which focuses on four major research lines: 1) variability in manifestation, 2) early diagnosis, 3) vascular factors, and 4) interventions. By answering research questions closely related to clinical practice, the results of our research can be looped back to improve clinical work-up for our patients.
\end{abstract}

Keywords: Alzheimer's disease, dementia, diagnosis, investigations, mild cognitive impairment, work-up

\section{INTRODUCTION}

The Alzheimer center of the VU University Medical Center (VUmc) opened its doors in 2000, when Philip

\footnotetext{
${ }^{*}$ Correspondence to: Philip Scheltens, Alzheimer Center PK -1 Z 44, VU University Medical Center, de Boelelaan 1118, $1081 \mathrm{HZ}$ Amsterdam, The Netherlands. Tel.: +31 20 4440816; Fax: +31 20 4440715; E-mail: p.scheltens@vumc.nl.
}

Scheltens, director of the Alzheimer center, accepted his full professorship. From the beginning, patient care and research went hand in hand at the VUmc Alzheimer center, both organized in such a way that they mutually strengthen each other. Over the years, the VUmc Alzheimer center has experienced a tremendous growth, but this founding principle is still at the core of its existence. In this paper, we will give an overview of the way we have organized patient care 
and research, in short: the Amsterdam approach. We will consecutively provide general information on the Alzheimer center, then focus on patient care, provide a detailed account of our standard diagnostic work-up that is at the core of both patient care and research, and finally describe our research efforts, ending with a number of examples.

\section{Mission and vision}

The VUmc Alzheimer center offers the highest level of referral in patient care and research. We strive for a leading position in both care and research, with a focus on dementia with early onset. Our mission is to give patients with dementia a voice by lifting the stigma on dementia, to achieve a better understanding of dementia, to find new diagnostic and therapeutic strategies and ultimately and hopefully, to cure diseases that cause dementia. The vision of the VUmc Alzheimer center is that only by combining patient care and research we will achieve the necessary progress in the battle against dementia.

\section{Organization}

The VUmc Alzheimer center is part of the department of Neurology of the VUmc. A management team of three is responsible for the daily operations. Staff includes five neurologists, two specialized nurses, and two senior researchers. Five postdoctoral fellows, more than $25 \mathrm{PhD}$ students, and four neuropsychology assistants are involved in research. In addition, the Alzheimer center closely collaborates with many departments and disciplines, including the departments of Radiology \& Nuclear Medicine, Clinical Chemistry, Clinical Neurophysiology, Geriatrics, Psychiatry, and Medical Psychology. All research activities are embedded in the Neuroscience Campus Amsterdam (http://www.neurosciencecampusamsterdam.nl/en/index.asp), the overarching institute hosting all 400+ neuroscientists of the VU University in Amsterdam.

\section{The building}

The VUmc Alzheimer center is housed in a dedicated unit within the outpatient building of the VUmc since September 2010, when the new facility was opened in the presence of her Majesty the queen of the Netherlands. A large grant of the Innovatiefonds Zorgverzekeraars (http://www. innovatiefondszorgverzekeraars.nl/) has enabled the

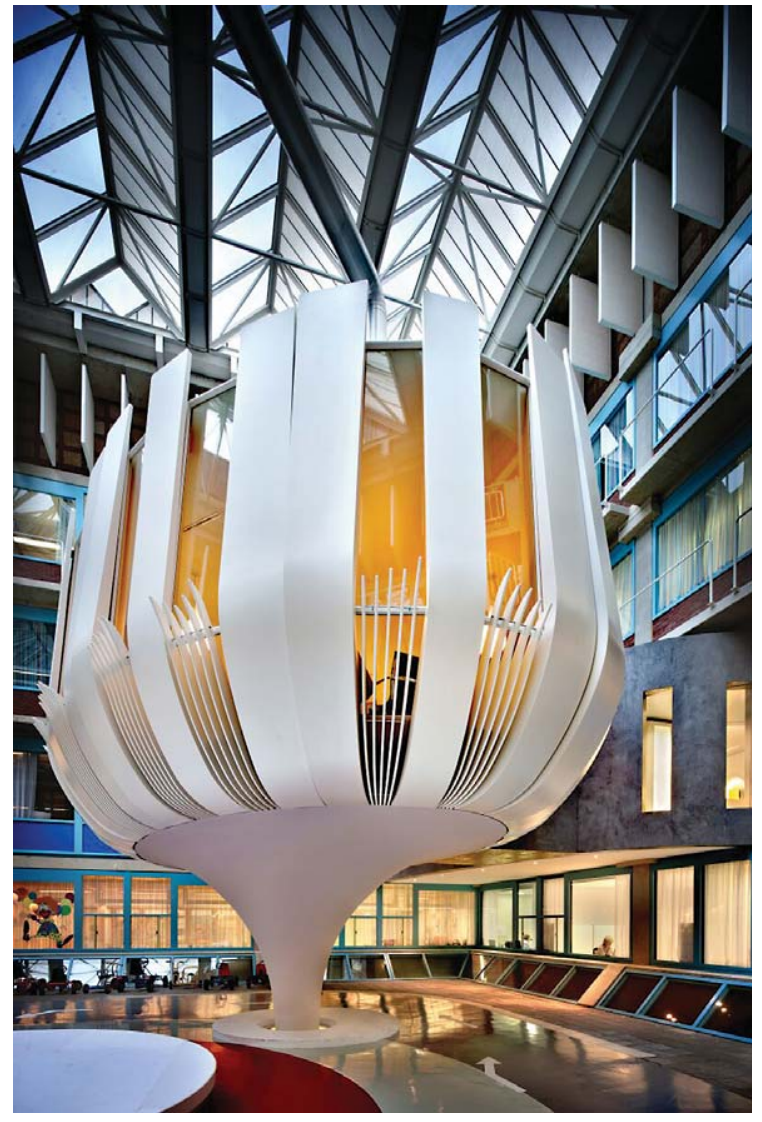

Fig. 1. The Alzheimer center has been designed and built by Leeuwenkamp Architects. The central and most remarkable part of the center is the patient lounge. Standing on a single steel pole, it looks like a lotus flower (or Dutch tulip) that 'envelops' the patients. It offers a safe area that gives comfort. This is where patients come in in the morning and are picked up for their appointments during the entire day. In between appointments, people can read magazines at the round table, chat with their family or fellow patients, or maybe relax a little by looking at the fish tank. Free lunch is served and coffee and tea are available throughout the day. All activities literally take place around the patient lounge, which reflects our motto that the patient is central in everything we do.

building of this center, specifically dedicated to patients with early onset dementia, and accessible to patients from the entire country. The Alzheimer center has been designed and built by Leeuwenkamp Architects, who took the 'bright sight concept' as a starting point. The bright sight concept brings a friendly, homelike look and feel to the hospital environment, to stimulate well-being of both the patients who visit us and the professionals who work in the center. The central and most remarkable part of the center is the 'patient lounge'. Standing on a single steel pole, it looks like a lotus flower (or Dutch tulip) that 'embraces' the patients (Fig. 1); it offers a safe area that gives comfort. 
This is where patients come in in the morning and are picked up for their appointments during the day. We offer all that is needed during the day to make the patients and their families feel at home. Staff offices are located one floor below. This reflects the idea that our patient care is strongly supported (literally) by our scientific efforts and that they are closely related.

\section{PATIENT CARE}

\section{Health care pathway}

The diagnostic assessment- the most important part of the health care pathway of the VUmc Alzheimer center-is organized in a unique, one-stop-shop fashion (Fig. 2). As a second unique feature, research has been systematically built into the health care pathway, thus fully integrating patient care and research. In brief, as is customary in the Netherlands, patients are referred for analysis of their cognitive complaints by their general practitioner or via their local specialist (more than half of our referrals are second or third opinions). Each week, 12 new patients are seen (600/year). Each patient receives the same standardized and multidisciplinary work-up. The diagnostic work up includes medical and neurological investigation including history taking and cognitive examination by a neurologist, assessment of vital functions, informant based history and assessment of needs by a specialized dementia nurse, neuropsychological investigation, brain magnetic resonance imaging (MRI), electroencephalogram (EEG), standard laboratory work, and lumbar puncture (see details below). All patients are asked for informed consent to store their clinical data in a database with the goal to use these data to answer research questions. In addition, we ask patients informed consent for the storage of biomaterial [blood (serum/plasma), DNA, cerebrospinal fluid (CSF)] in our biobank. The local Medical Ethics Committee has approved a general protocol for biobanking and using the clinical data for research purposes. Patients and their family also receive explanation about the possibility to donate their brain to the Netherlands Brain Bank.

At the end of the same week, all professionals convene in our weekly round-table, multidisciplinary meeting and each presents his or her findings in a structured way. A clinical diagnosis and treatment plan is made by consensus. At the time of initial diagnosis, results of lumbar puncture are not yet available. If necessary, these results are awaited and/or ancillary investigations, such as a consultation by the psychiatrist or a PET scan (e.g., glucose metabolism, amyloid) or a dopamine transporter SPECT scan are planned. Diagnoses are made according to current clinical criteria. We use common clinical and research criteria for all the major dementias [1-7]. For mild cognitive impairment (MCI), Petersen's criteria had been used until the beginning of 2012, when we started using the National Institute on Aging-Alzheimer's Association (NIA-AA) criteria for MCI [8, 9]. Patients are labeled as having a psychiatric disorder when, based on thorough investigation, a neurodegenerative disease seems unlikely, and clinically there is a suspicion of a psychiatric disorder. These patients are subsequently referred to a psychiatrist. Patients with a neurological disorder other than any of the dementias mentioned above as primary diagnosis are referred to as 'Neurology Other'. When the clinical picture in combination with the results of ancillary investigation do not provide sufficient information to reach consensus, the diagnosis is labeled as Unclear/Postponed. Patients are labeled as having Subjective Complaints when they present with cognitive complaints, but cognitive and laboratory investigations are normal and criteria for MCI, dementia, or any other neurological or psychiatric disorder known to cause cognitive complaints are not met (i.e., cognitively normal). On a yearly basis, we see roughly 600 new patients. The patients we see are relatively young and most are in a relatively early disease stage. Older patients (arbitrarily set at older than 75 years) or patients with significant comorbidity are generally referred to the department of Geriatrics, whose diagnostic work-up is very much aligned to ours.

At the time of the multidisciplinary meeting, the database team checks whether informed consent has been provided and, if yes, whether all information has been entered into the research database by a commissioned database team. In addition, the database team screens patients for eligibility to participate in specific research projects (both observational studies and clinical trials).

One week after the initial visit, patients return to discuss results of the diagnostic procedure. The neurologist explains all test results and the diagnosis and treatment plan is discussed. We provide written information about the different types of dementia and MCI. These informational documents also contain useful websites and the contact details of patient organizations such as the Dutch Alzheimer Association. At this time, the specialized dementia nurse is on stand-by to provide immediate care and/or help with implementation of the care plan. Also, patients interested in participating in research can immediately be referred 
Timeline

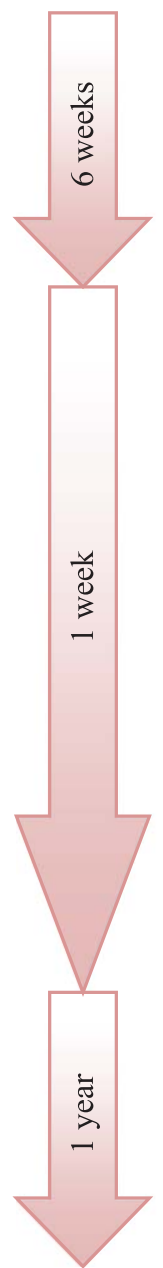

patient care

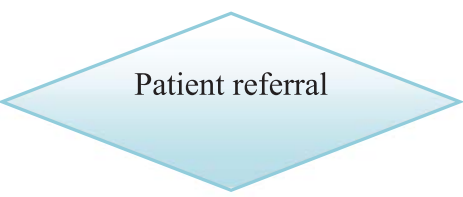

Screening day:

- Neurologist

- Vital functions

- Spec nurse

- Neuropsych inv.

- MRI

- EEG

- Blood

- Lumbar puncture

Multidisciplinary meeting: diagnosis and treatment plan

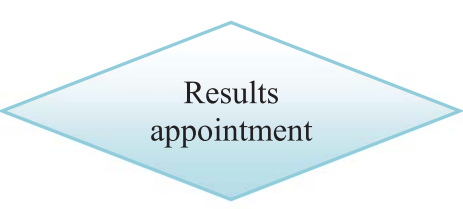

Annual follow-up research

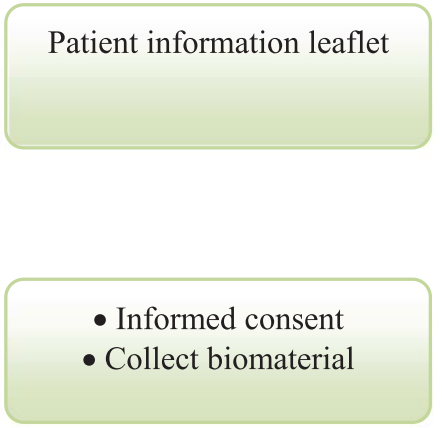

- Check informed consent

- Database entry

- Identify patients eligible for studies

Interview research desk

Fig. 2. The flow chart illustrates the health care pathway of the VUmc Alzheimer center. The diagnostic work-up has been organized in such a way that all necessary investigations take place on one day, resulting in a diagnostic process which takes only one week from first visit to discussing results with the patient (see red arrows for timeline). In addition, the green pathway shows that research is fully integrated in the clinical work-up, as patients are being asked for their consent to use their clinical data for research purposes. This results in the VUmc Alzheimer center approach, where patient care and research go hand in hand. The number of new patients that follow this path is 600/year. Return visits are on average 2/year/patient, hence 1200/year. $70 \%$ of the patients presenting have an early onset of symptoms (<70 years of age).

to the 'research desk' to receive information about ongoing studies for which they are deemed eligible.

Clinical and research follow-up depends on a number of factors, including the specific diagnosis, the patients' preferences, and participation in research programs. In general, we have organized our follow-up in such a way that patients are monitored on an annual basis in a standardized fashion. The standardized follow-up includes a follow-up visit with the neurologist, neuropsychologist, and nurse. The diagnosis and treatment plan are re-evaluated in a small multidisciplinary meeting of the professionals involved. In between annual visits, tailor made neurological consultations are scheduled. During the disease course, the dementia nurses can be consulted as needed.

\section{DIGITAL ALZHEIMER CENTER}

To date, there is no cure for Alzheimer's disease (AD), or any of the other dementia syndromes. In addition to available symptomatic medication, providing and organizing good care is still among the most important interventions affecting quality of life of patients and their caregivers. As an academic, tertiary 
referral center, the VUmc Alzheimer center is not equipped to provide day-to-day care for our patients. Since most patients visiting the Alzheimer center come from outside the region, care is arranged locally. Yet, with the advance of e-health facilities, we feel we can bring our care closer to the patient. This innovative concept has resulted in the development of a web-based portal, the Digital Alzheimer Center (DAC) (http://www.digitaalalzheimercentrum.nl), which can be viewed directly or after visiting the general website of the center: http://www.alzheimercentrum.nl/.

After a survey among patients, caregivers, and professionals, we came to the following needs that were to be met by a patient-portal: easily accessible, comprehensive information on dementia disorders and how to deal with it in daily life, support not only by professionals but also through exchange of experiences with fellow-sufferers, and direct contact with the Alzheimer center professionals. The general website already contains a lot of useful information accessible to everybody, but the portal is exclusively for patients of the Alzheimer center and their caregivers and can only be accessed by login with a unique password. In the context of the Dutch national 'Deltaplan Dementie', we aim to open up the portal to all patients, as part of a national portal, yet to be created. There is an extensive menu containing information on diseases, illustrated with animations to clarify pathological processes. Patients and caregivers can find practical tips on living with the changes that are caused by the disease, financial and legal matters, and how to avoid caregiver stress, among many more. A community hosts a forum for questions, exchanging experiences (also photos and videos), and information among patients, caregivers, and health care professionals. In the community, upcoming events and news from the Alzheimer center or the (inter)national Alzheimer community are communicated. Our nurses host biweekly chat-sessions on various topics. In a specially secured section, patients can email with health care professionals, view their appointments and medical correspondence, and will soon have the opportunity to consult their doctor from their own homes by video connection. A dedicated team of the Alzheimer center, in which patients and caregivers participated throughout the process, developed the DAC and is still involved in the continued improvement. In order to optimize the use of the portal, every 3 months workshops are organized in which the various functionalities of the DAC are explained and participants can practice hands-on. The portal was launched in January 2012 and currently has over 1,000 users.

\section{STANDARD WORK-UP}

In the section below, we give a detailed description of the investigations that are performed as part of our routine diagnostic screening. For diagnostic purposes, the results of the investigations are often used on a qualitative fashion. Here, we give a research-oriented description, as these measurements are used in many of our studies and publications, focusing on the quantitative metrics we obtain from them.

\section{Vital functions and questionnaires}

Blood pressure, height, weight, and waist size are measured in a standardized fashion.

Behavioral and psychological symptoms of dementia are assessed by the Neuropsychiatric Inventory [10]. Depressive symptoms are additionally assessed by the abbreviated Geriatric Depression Scale [11]. For the assessment of activities of daily living, we use the Disability Assessment for Dementia, and the Amsterdam Instrumental Activities of Daily Living questionnaire [12-14]. We use the Clinical Dementia Rating to provide an estimate of disease severity [15].

\section{Neuropsychological assessment}

Cognitive functions are assessed with a standardized test battery, which takes roughly one hour to perform. We use the Mini-Mental State Examination (MMSE) and the Cambridge Cognitive Examination for global cognitive decline $[16,17]$. For memory, we use the Visual Association Test (VAT) and total immediate recall and delayed recall of the Dutch version of the Rey auditory verbal learning task [18-20]. To examine language, we use VAT naming, category fluency (animals), and the Dutch version of Controlled Oral Word Association Test (letter fluency), the latter two of which also tap on executive functioning [20-22]. We use three subtests of the Visual Object and Space Perception Battery to assess visuospatial functioning, namely (i) incomplete letters, (ii) dot counting, and (iii) number location [23]. For the attention domain, we use Trail Making Test (TMT) A and the forward condition of Digit Span (extended version) [24, 25]. We use TMT B and the backwards condition of Digit Span (extended version) to examine executive functioning $[24,25]$. If deemed necessary by the team, slots for more extensive neuropsychological investigation are available, with the selection of neuropsychological tests tailored to the differential diagnosis at hand. 
At present, MRI of the brain is acquired on one of our 3T whole body MR systems (MR750, GE Medical Systems, Milwaukee, WI, USA; Ingenuity TF PET/MR (the first and only PET/MR system in the Netherlands), Philips Medical Systems, Best, The Netherlands; Titan, Toshiba Medical Systems, Japan). In the past, 1.0 and $1.5 \mathrm{~T}$ systems have been used as well (Siemens Magnetom Impact and Sonata, GE Healthcare Signa HDXT). The standard MRI protocol includes a sagittal 3D heavily T1-weighted gradient-echo sequence with coronal reformats, a sagittal 3D T2-weighted fluid-attenuated inversionrecovery (FLAIR) turbo/fast spin-echo with axial reformats, a transverse T2-weighted turbo/fast spinecho, a transverse $\mathrm{T} 2 *$ susceptibility sequence, and diffusion weighted imaging/EPI. All sequences are performed with whole brain coverage. In addition, the protocol can be extended with novel sequences, such as arterial spin labeling (ASL) or diffusion tensor imaging (DTI).

An experienced neuroradiologist reviews all scans. As part of our standard work-up, we perform a visual rating for all patients. Atrophy of the medial temporal lobe (MTA) is rated on the coronal reconstructions of the T1-weighted scan using a 5-point visual rating scale (0-4) based on the height of the hippocampal formation and the width of the choroid fissure and the temporal horn [26]. Posterior atrophy is rated on the combination of T1-weighted and FLAIR sequences using a 4-point visual rating scale $(0-3)$ based on the posterior cingulate and parieto-occipital sulcus and sulci of the parietal lobes and precuneus [27, 28]. Global cortical atrophy is rated on the FLAIR using a 4-point visual rating scale (0-3) [29]. On FLAIR, white matter hyperintensities are rated using the Fazekas scale and classified as punctuate (grade 1), beginning confluent (grade 2), or confluent (grade 3) [30]. Lacunes are counted and defined as deep lesions $(3-15 \mathrm{~mm})$, with (CSF-like) low signal on T1-weighted sequences and high signal on T2-weighted sequences. Microbleeds are counted on $\mathrm{T} 2 *$ sequences and are defined as small round foci of hypointense signal, up to $10 \mathrm{~mm}$ in brain parenchyma [31]. Raters are trained based on available scans and have to perform the test set consisting of 19 MRI scans before they are allowed to perform visual ratings. Inter- and intrarater weighted kappas of at least 0.80 for MTA, 0.60 for global cortical atrophy, and 0.70 for Fazekas (against internally established gold standard) are required [32]. For microbleed count, weighted Cohen's kappa are $>0.90[31,32]$.
EEGs are recorded using a digital EEG system and software (Brain RT ${ }^{\circledR}$; OSG b.v., Rumst, Belgium) at the positions of the 10-20 system: Fp2, Fp1, F8 F7, F4, F3, A2, A1, T4, T3, C4, C3, T6, T5, P4, P3, O2, O1, Fz, Cz, Pz. Sample frequency is $500 \mathrm{~Hz}$. Electrode impedance is below $5 \mathrm{k} \Omega$ and initial filter settings are: time constant $1 \mathrm{~s}$; low pass filter, $70 \mathrm{~Hz}$. Patients are seated in a slightly reclined chair in a sound attenuated room. Patients sit mainly with eyes closed; EEG technicians are alert on keeping patients awake by sound stimuli. Board certified clinical neurophysiologists assess all EEG recordings.

In addition to the usual EEG report, all EEGs are rated according to a standard visual rating scheme [33, 34]. The visual rating includes 1 ) a rating of severity of EEG abnormalities on a 4-point scale, ranging from no abnormalities to severe abnormalities, and presence of 2) focal abnormalities, 3) diffuse abnormalities and 4) epileptiform abnormalities. Presence of focal abnormalities is defined as (transients of) slow or sharp wave activity in 1 or more EEG leads, not taking into account benign temporal theta of the elderly. Presence of diffuse abnormalities is defined as a dominant frequency of rhythmic background activity below $8 \mathrm{~Hz}$, diffuse slow-wave activity or diminished reactivity of the rhythmic background activity to the opening of the eyes. In previous reports by our study group kappavalues for inter observer agreement between 0.60 and 0.87 have been reported [33].

\section{Blood and CSF}

In addition to collection of body fluids for routine lab analysis, blood (serum and plasma), DNA, and CSF are obtained and stored in our biobank.

\section{Blood}

Venous blood (2-6 $\mathrm{ml}$ clotted blood for serum and $6 \mathrm{ml}$ EDTA blood for plasma) is processed and stored according to international consensus standard operation procedures [35]. Samples are aliquoted into $0.5 \mathrm{ml}$ samples and stored at $-80^{\circ} \mathrm{C}$.

\section{DNA}

2-4 ml EDTA whole blood is collected for DNA extraction. In addition and on a routine basis, Apolipoprotein E (APOE) genotyping is performed using a QIAxcel DNA Fast Analysis kit (Qiagen, Venlo, The Netherlands). 


\section{CSF}

CSF is collected by lumbar puncture between the L3/L4, L4/L5 or L5/S1 intervertebral space by a 25-gauge needle and syringe and collected in polypropylene tubes. CSF is centrifuged at $1800 \mathrm{~g}$ for $10 \mathrm{~min}$ at $4^{\circ} \mathrm{C}$. Part of the $\mathrm{CSF}$ is used for routine analysis including leukocyte count, erythrocyte count, glucose concentration, and total amount of protein and, frozen at $-20^{\circ} \mathrm{C}$ until analysis of standard Alzheimer biomarkers (within two months). The remainder of the CSF is directly transferred to the Alzheimer center Biobank at the department of Clinical Chemistry, and processed according to international guidelines, in aliquots of $0.5 \mathrm{ml}$ at $-80^{\circ} \mathrm{C}$ [35]. CSF biomarker analysis takes place on a biweekly basis at the Neurochemistry laboratory of the department of Clinical Chemistry of the VUmc. Amyloid- $\beta$ 1-42 (A $\left.\beta_{42}\right)$, total tau, and tau phosphorylated at threonine 181 ( tau) are routinely measured using sandwich ELISAs (Innotest, beta-amyloid1-42, Innotest hTAU-Ag and Innotest PhosphoTAU-181p, Innogenetics, Belgium) [36]. The performance of these assays is monitored with two internal quality control pools of surplus CSF (high and low biomarker values). Inter-assay $\mathrm{CVs}$ $\left(\right.$ mean $\pm \mathrm{SD}$ ) were $10.9 \pm 1.8 \%$ for $\mathrm{A} \beta_{42}, 9.9 \pm 2.1 \%$ for tau, and $9.1 \pm 1.8 \%$ for $\mathrm{p}$-tau, as analyzed in a high and low pool from 13 consecutive pool preparations of two surplus CSF specimens (one normal and one AD profile), used in total in 189-231 runs.

\section{PET}

PET is not part of our routine work-up, but $\left[{ }^{18} \mathrm{~F}\right] \mathrm{FDG}$ measuring glucose metabolism is performed in case of a diagnostic dilemma. Amyloid PET (with the tracers $\left[{ }^{11} \mathrm{C}\right] \mathrm{PIB},\left[{ }^{18} \mathrm{~F}\right]$ Flutemetamol, $\left[{ }^{18} \mathrm{~F}\right]$ Florbetapir, and $\left[{ }^{18} \mathrm{~F}\right]$ Florbetaben) is available and is mostly performed as part of research programs and sometimes in the context of patient care. PET-scanners include the Gemini TF PET-CT, Ingenuity TF PET-CT, and Ingenuity PET/MRI system (all Philips Medical Systems, Best, The Netherlands). For $\left[{ }^{18} \mathrm{~F}\right] \mathrm{FDG}$, patients rest for $15 \mathrm{~min}$ before injection and $35 \mathrm{~min}$ after injection under standard conditions (eyes closed in dimmed ambient light). Next, patients undergo a 15-min emission scan. Parametric images of standardized uptake value ratios (SUVr; cerebellum as reference tissue) are extracted from the interval between 45 and $60 \mathrm{~min}$ after injection and are interpreted visually. For clinical amyloid scanning, we perform a comparable SUVr approach (for $\left[{ }^{11} \mathrm{C}\right] \mathrm{PIB}$ an interval of 60 to $90 \mathrm{~min}$ is used, for $\left[{ }^{18} \mathrm{~F}\right]$ Flutemetamol the image acquisition window extends from 85 to $115 \mathrm{~min}$ ). For $\left[{ }^{11} \mathrm{C}\right] \mathrm{PIB}$, quantitative $\mathrm{BP}_{\mathrm{ND}}$ (a measure of specific binding), parametric maps can be generated but then a dynamic 90-min emission scan is necessary. For clinical purposes, all amyloid scans are read binary, i.e., rated as positive or negative.

\section{RESEARCH}

\section{Amsterdam dementia cohort}

The medical ethical committee of the VU University Medical Center has approved both the generic protocol describing the use clinical data for research purposes and the biobanking protocol. Ninety-nine percent $(99 \%)$ of our patients provide informed consent for the use of their clinical data for research purposes. Informed consent for biobanking is provided in roughly 3 out of 4 of patients. All clinical data are entered in our database, which to date includes $>4000$ patients, and together these patients form the 'Amsterdam Dementia Cohort'.

The database serves three purposes: 1) For basic research questions, e.g., regarding neuropsychological data, visual MRI ratings, or regular CSF biomarkers, data can be directly extracted from the database; 2) For other research questions, e.g., including sophisticated analyses on neuroimaging or identification and validation of novel biomarkers, the database serves as a starting point to identify patients fulfilling inclusion criteria with available neuroimaging or biomaterial; 3 ) Finally, the database can be interrogated to identify patients who may be interested to participate in a new study, since patients indicate in their informed consent form whether they may be approached for future research.

To date, the Amsterdam Dementia Cohort includes well over 4000 patients (Table 1). Slightly less than half of patients are female (44\%). On average, patients are $64 \pm 10$ years old. In the entire group, $55 \%$ are 65 or younger at first presentation. Average MMSE is $24 \pm 5 ; 43 \%$ receive an initial diagnosis of dementia. The pie chart shows the distribution of diagnoses (Fig. 3). AD is the most common diagnosis, followed by subjective complaints and MCI. MRI is available for well over 3000 patients, EEG for more than 3500 patients, and biomaterial for more than 3000. $\left[{ }^{18} \mathrm{~F}\right] \mathrm{FDG}$ and, amyloid PET $\left(\left[{ }^{11} \mathrm{C}\right] \mathrm{PIB}\right.$, $\left[{ }^{18} \mathrm{~F}\right]$ Flutemetamol, $\left[{ }^{18} \mathrm{~F}\right]$ Florbetapir), are available for roughly 400 patients. Magneto-encephalography (MEG) and resting-state functional MRI are 


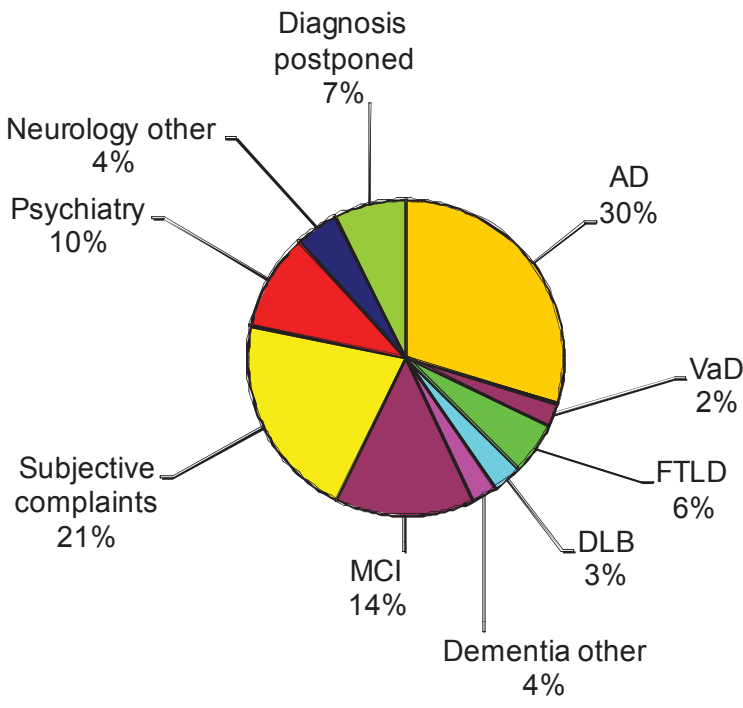

Fig. 3. The pie chart shows all initial diagnoses in the Amsterdam Dementia Cohort, containing 4016 patients in August 2013. The most frequently made diagnosis is AD, followed by subjective complaints and mild cognitive impairment. Due to the relatively young age of the patients visiting our center, more rare diagnoses such as frontotemporal dementia are relatively frequent. $\mathrm{AD}$, probable and possible Alzheimer's disease; VaD, vascular dementia; FTLD, frontotemporal lobar degeneration, includes both behavioral variant FTD and primary progressive aphasia; DLB, dementia with Lewy bodies; Dementia other include other types of dementia such as Creutzfeldt Jacob disease, corticobasal degeneration, progressive supranuclear palsy, and alcohol dementia; MCI, mild cognitive impairment.

Table 1

Demographic characteristics of the Amsterdam Dementia Cohort

\begin{tabular}{lc}
\hline $\mathrm{n}$ & 4016 \\
Gender, F & $1769(44 \%)$ \\
Age, years & $64 \pm 10$ \\
Age, $\leq 65$ years & $2213(55 \%)$ \\
MMSE & $24 \pm 5$ \\
Availability & \\
MRI & $3198(80 \%)$ \\
EEG & $3570(89 \%)$ \\
Biomaterial (CSF, blood, DNA) & $2687(67 \%)$ \\
\hline
\end{tabular}

Data are represented as mean \pm standard deviation or $\mathrm{n}(\%)$. The Amsterdam Dementia Cohort is the ongoing study attached to the memory clinic of the VUmc Alzheimer center. Numbers presented were derived from the database in August 2013.

available for a subset of patients as well as microglia ([ $\left.\left.{ }^{11} \mathrm{C}\right] \mathrm{PK} 11195\right)$ and $\mathrm{PgP}\left(\left[{ }^{11} \mathrm{C}\right]\right.$ Verapamil $)$ PET.

\section{Research lines}

As a direct consequence of its organization, the VUmc Alzheimer center mainly performs clinical research. Research questions are closely related to clinical questions. Consequently, research results can be used to further optimize patient care at a fairly swift pace. The research activities of the VUmc Alzheimer center are centered around four research lines.

1. Variability in manifestation. Apart from variation in phenotypes between dementia subtypes, there is considerable heterogeneity within dementia subtypes, such as $\mathrm{AD}$. In most AD patients memory impairment is the first and most salient symptom, but in others, memory is relatively spared while, for example, visuospatial functioning, executive functioning, or language show early impairment. Patients with early disease onset relatively often have these atypical presentations. This research line focuses on identifying biological mechanisms explaining heterogeneity in clinical manifestation in AD and other dementias. It takes as a starting point the assumption that we will never find one drug that will cure all dementia patients ('magic bullet'). Rather, compounds may be effective for specific subgroups of patients (personalized medicine). The underlying hypothesis is that dementia due to $\mathrm{AD}$ is a common downstream stage that may be reached along different pathways, each requiring their own therapeutic strategy. Differences in biological factors between specific patient groups may offer targets for the development of novel compounds, starting point of stratified analyses, and ultimately help develop personalized treatment. This research line also addresses differences between different types of dementia (differential diagnosis).

2. Early diagnosis. This research line aims to develop novel methods that may aid in the early diagnosis of $\mathrm{AD}$ and other types of dementia. It has become clear that $\mathrm{AD}$ has a long pre-dementia phase where neuropathological changes start to accumulate 15 to 20 years before onset of dementia [37]. In the past decade, research focusing on early diagnosis has increasingly targeted patients with MCI. We currently see a shift toward even earlier in the disease process, i.e., preclinical AD. In the context of the memory clinic based Amsterdam Dementia Cohort, this means that we aim to follow patients with subjective complaints over time to identify predictors of clinical progression. In addition, we study patients presenting with different, non-memory symptoms, such as patients presenting with behavioral changes, in the Late Onset Frontal lobe syndrome cohort. The latter is one of the research projects we run and constitutes the study of patients presenting with a frontal lobe syndrome into the (various) underlying pathologies [38]. The possibility to measure $A \beta$ and tau using CSF biomarkers or amyloid PET has acted as an important catalyst. In the context of these earliest changes ultimately leading to dementia 
due to $\mathrm{AD}$, research focusing on protective factors and resilience (for example due to cognitive reserve), to answer the question why some individuals are capable of handling a higher amyloid load than others, is now also feasible. In addition, in the context of this research line we study natural disease course and aim to identify prognostic biomarkers and biomarkers reflecting disease progression.

3. Vascular factors. Dementia, especially at old age, is often caused by mixed pathology. Next to $\mathrm{AD}$ as main cause of cognitive decline, cerebrovascular disease, especially small vessel disease, is a main determinant, nowadays often captured under the umbrella term Vascular Cognitive Impairment. This research line studies how small vessel disease and neurodegenerative brain changes act in synergy to cause dementia. In the past decades, research has mostly focused on ischemic small vessel disease (i.e., white matter hyperintensities and lacunes on MRI). Recently, we increasingly focus on cerebral amyloid angiopathy, sometimes visible on MRI as microbleeds. This amyloid pathology in the vessels is a likely candidate to form a direct link between the two types of pathology. Two aspects of the new generation of anti-amyloid immunotherapy have further boosted interest in this research line: 1) anti-amyloid therapy has resulted in an increased rate of vascular damage such as microbleeds, potentially due to removal of amyloid through vessel wall and 2) anti-amyloid therapy has until now not been very successful in improving patient outcome, leaving room for other drug targets such as the brain vasculature. We were the first to identify that the activity of the efflux pump PgP in the blood-brain barrier is decreased in sporadic AD [39].
In this research line, we make use of novel imaging techniques, such as ASL perfusion MRI, DTI MRI, and resting state functional MRI, to gain more insight in the mechanisms underlying the association between cerebral small vessel disease and cognitive decline and dementia [40-42]. Decreased cerebral perfusion and impaired structural and functional connectivity may reflect the combined disease burden of both cerebral small vessel disease and AD pathology. Furthermore, the specific location and severity of cerebrovascular damage in individual patients is likely to be related to damage to specific neuronal networks and neurotransmitter systems, opening up the possibility of tailor made symptomatic treatment.

4. Therapy. This research line is dedicated to finding innovative therapy and includes both pharmacological and non-pharmacological interventions. Our research efforts concerning pharmacological therapy largely consist of contract research and take place at the Alzheimer Research Center (http://arcresearch.eu/), a separate unit specifically dedicated to Phase 2 and 3 clinical trials (see below). In addition to medication, other (lifestyle) factors can also influence the course and symptomatology of dementia. Examples of investigator initiated studies include studies on the effect of physical activity, light and medical food [43-46].

All research questions are targeted using one or more specific techniques, i.e., cognition, MRI, PET, EEG/MEG, biomarkers, genetics, and pathology. Combining the four research lines and seven techniques, results in our research matrix (Fig. 4). Each study, project, or paper fits into a cell, row, or column of the matrix.

\begin{tabular}{|l|l|l|l|l|}
\hline Cognition & $\begin{array}{l}\text { (1) Variability } \\
\text { in manifestation }\end{array}$ & $\begin{array}{l}\text { (2) Early } \\
\text { diagnosis }\end{array}$ & $\begin{array}{l}\text { (3) Vascular } \\
\text { factors }\end{array}$ & (4) Interventions \\
\hline MRI & & & \\
\hline PET & & & \\
\hline EEG/MEG & & & \\
\hline Biomarkers & & & \\
\hline Genetics & & & \\
\hline Pathology & & & \\
\hline
\end{tabular}

Fig. 4. The research activities of the Vumc Alzheimer center are centered around four research lines: 1) variability in manifestation, 2) early diagnosis, 3) vascular factors, and 4) interventions. All research questions are targeted using one or more specific techniques, i.e., cognition, MRI, PET, EEG/MEG, biomarkers, genetics, and pathology. Combining the four research lines and seven techniques, results in our research matrix. Each study, project, or paper fits into a cell, row, or column of the matrix. 


\section{Alzheimer research center}

The Alzheimer Research Center (ARC; http://arcresearch.eu/) is the clinical trial center of the VUmc Alzheimer Center and was established in 2010. The ARC is a center of excellence for Phase 2 and 3 clinical trials in AD and other dementias. There are two main reasons why there is a need for specialized trial centers such as the ARC. First, AD trials, in particular those with disease modifying therapy, are becoming increasingly complex. Assessments often include specialized neuropsychological testing, amyloid-PET imaging, and cerebrospinal fluid sampling, and demand sufficient manpower of specialized personnel. Second, patient recruitment for $\mathrm{AD}$ trials is challenging, since the field is moving more and more toward the prodromal or even preclinical stages of the disease, and these patients are not easy to identify. A specialized trial center is able to meet these demands. The team of the ARC includes neurologists, trial nurses, neuropsychologists, and laboratory specialists. Services of the ARC include patient examination, treatment, and monitoring, MRI examinations in close collaboration with the Image Analysis Center (IAC) VUmc, and amyloid-PET imaging in collaboration with the PET center VUmc. The ARC also offers protocol submission and approval from Ethical Review Boards. Apart from the VUmc Alzheimer Center, the ARC has also partnered with the Center for Human Drug Research (CHDR) in Leiden. CHDR provides trial services for Phase 1 clinical trials in AD. The ARC has been or is involved in trials with monoclonal antibodies in $\mathrm{AD}$ and in prodromal $\mathrm{AD}$, with $\mathrm{BACE}$ inhibitors in early $\mathrm{AD}$ and in mild to moderate $\mathrm{AD}$, with active vaccination in $\mathrm{AD}$, with a medical food in $\mathrm{AD}$, and with a tau aggregation inhibitor in frontotemporal dementia.

\section{Neuroscience campus amsterdam}

The research at our Alzheimer Center is embedded in the Neuroscience Campus Amsterdam (NCA; http:// www.neurosciencecampus-amsterdam.nl), a network organization between four faculties (Medicine, Psychology, Earth and Life Science, and Exact Sciences) within the VU University. Its mission is to study the brain and its disease mechanisms through an integrative approach ranging from molecule-to-bedside. Scientists at the NCA apply a systems biology approach to the brain where clinicians and clinical researchers are working side-by-side with neuroscientists, geneticists, psychologists, biophysicists, and statisticians. Through this collaboration, the NCA delivers proof-of-concept for radically new approaches in the early diagnosis of brain disease and the elucidation of its underlying mechanisms, thus providing new perspectives on therapy. The NCA has five main programs, of which the 'Neurodegeneration program' hosts all research of the Alzheimer Center.

\section{Research desk: Dissemination and outreach}

Our motto is that patient care and research go hand in hand. Our research efforts would be nothing if not for the continuous contribution from all patients visiting our center. As such, we find it extremely important to include patients and the community as much as we can and to keep them up to date on the results of our research activities. The 'Alzheimer center research desk' has been developed specifically for this purpose. The research desk informs patients about the possibilities to participate in research by announcements on the website, in the patient lounge, and during personal interviews. Results of studies are disseminated via news items on our website, regular newsletters to specific cohorts of patients, and freely accessible 'lunch\&learn' meetings. The lunch\&learn meetings are offered every two months. The facilitator may be a nurse or a physician depending on the subject. In the past two years, we have had meetings on driving license issues, legal issues, mental capacity issues, the digital Alzheimer center, nutrition, end of life decision making, etc., all topics of interest to patients with dementia and their caregivers. In addition, people working at the Alzheimer center give lectures in 'Alzheimer cafés', schools, etc. on a regular basis. Patient participation in the development of our research program and activities is realized by asking input on a regular basis from a platform of patients and caregivers. For professionals, the research desk organizes educational activities including symposia for national professionals and preceptorships for groups of foreign colleagues.

\section{FROM CARE TO RESEARCH ... AND BACK}

Using clinical data to answer research questions, our research questions are inevitably closely linked to questions that arise in clinical practice. As a consequence, the feedback loop from research to improving patient care is relatively short. Here, we give four historical examples.

In the early nineties, with the advance of MR imaging, it became possible for the first time to measure the actual changes taking place in the brain of 
living patients. Increasing evidence pointed at the MTA, including the hippocampus and parahippocampal gyrus as places of early atrophy. Measurement of the volumes of these structures was often time and labor intensive, hence not easily applicable in clinical practice. As a PhD student, Philip Scheltens developed a simple, visual rating scale for atrophy of the MTA [26]. Sensitivity and specificity of this simple rating scale were in the same order of magnitude as those of volumetric measurements, illustrating its reliability. In the 1984 research criteria, neuroimaging was recommended at least once during the diagnostic process, with the rationale to exclude other possible causes of cognitive decline [1]. As a result of accumulating evidence for prominent hippocampal atrophy, an inclusionary approach where neuroimaging may actually provide positive evidence for the presence of $\mathrm{AD}$ pathology has been increasingly advocated [47]. The MTA Scheltens scale has recently celebrated its 20th birthday and is still alive [48]. This simple tool that was developed for research purposes 20 years ago is used by many as part of their daily clinical routine [49]. Courses on how to perform the visual rating scales are still offered on a regular basis and we get visits from colleagues from all over the world to learn how to use the visual rating scales.

Around the turn of the century, it became possible for the first time to measure the proteins $A \beta$ and (phosphorylated) tau in CSF. Right from this time, the VUmc Alzheimer center decided to start a biobank collecting body fluids in collaboration with the Biobank of the department of Clinical Chemistry. In the course of the past decade, CSF biomarkers have shown good diagnostic value, as well as prognostic value for incident $\mathrm{AD}$, although the latter not perfect [36, 50-52]. CSF biomarkers have greatly advanced the field, as now for the first time, it was possible to measure $\mathrm{AD}$ pathology in living patients. Still, there are drawbacks: although performing well in single, experienced labs, there is large variability in biomarker concentrations and cut-offs between labs. Our Alzheimer center has therefore initiated one of the first quality control rounds and actively participates in ongoing quality control programs [53-57]. Philip Scheltens and Pieter Jelle Visser have actively contributed to the launching of the new research criteria of the IWG group and participated in the drafting of the new diagnostic criteria under auspices of NIA-AA. In both sets of criteria, CSF biomarkers have now been incorporated as markers providing evidence of the Alzheimer pathophysiological process, 'when available and deemed appropriate by the clinician' $[2,9,58,59]$. Thus, biomarkers that were discovered only 15 years ago are now being used in clinical practice. In our own diagnostic work-up, we do not yet use the results of CSF biomarkers for the initial diagnosis, but CSF results are reviewed at a later stage, to evaluate whether they are congruent with the clinical diagnosis.

In 2004, two PET-tracers claiming to bind to AD pathology became available. Although both $\left[{ }^{18} \mathrm{~F}\right]$ FDDNP and [ $\left.{ }^{11} \mathrm{C}\right] \mathrm{PIB}$ claimed to measure the same underlying pathology, they had not been compared on a side by side basis until this research question was addressed at the VUmc Alzheimer center. The comparison showed a modest correlation, illustrating that the two tracers bound to different, but related targets [60]. PIB clearly outperformed FDDNP at discriminating patient groups. FDDNP seemed to bind to tau as well and gave a hint of stronger correlation with severity of symptoms, although this could not be confirmed at follow-up [61-63]. Like CSF biomarkers, and even on a faster track, amyloid imaging has now also been incorporated in the new NIA-AA criteria. Approval by FDA and EMA of all three amyloid $\left[{ }^{18} \mathrm{~F}\right]$ tracers is well underway, facilitating their use and guidelines for appropriate use of amyloid imaging are being published [64]. One of the biggest issues surrounding amyloid imaging is the finding that $20 \%-30 \%$ of cognitively normal elderly prove to have amyloid on imaging $[65,66]$. Since the predictive value of these findings is not clear yet, it is not advised to use amyloid imaging in a clinical setting on a large scale basis. In addition, as imaging costs are high, and there is no medication available, there is currently debate on whether, how, and when to use amyloid imaging in clinical practice. Still, the possibility of amyloid imaging has already changed the diagnostic landscape.

In 2005 we started to count the hitherto considered insignificant, black dots on T2* MRI, also called microbleeds. We found a clearly higher prevalence of microbleeds in patients with $\mathrm{AD}$, probably due to concomitant cerebral amyloid angiopathy [31]. Their clinical relevance was not clear, but we and others showed them to be related to higher risk of mortality, though inconsistently to impaired cognition [32, 67, 68]. The most important risk factor for developing a microbleed was having microbleeds at baseline [69]. Microbleeds may have special relevance in AD as they may form a bridge between $\mathrm{AD}$ pathology and small vessel disease (often literally reflecting AD pathology in the vessel walls) [70]. The interest in microbleeds was further boosted by their occurrence as side effects in amyloid immunization trials [71, 72]. The Amsterdam Dementia Cohort is one of the few 
worldwide that allows the study of natural progression of microbleeds in AD. Many questions still surround microbleeds, such as whether they infer an increased risk of large hemorrhage and whether their observation should hence affect treatment, for example with anticoagulant therapy. We are currently addressing these questions in the ongoing MISTRAL study.

\section{CONCLUSIONS}

The VUmc Alzheimer center has organized patient care and research in such a way that they mutually benefit and strengthen each other. In this way, we have built the Amsterdam Dementia Cohort, which to date includes over 4000 patients, with biomaterials and deep phenotyping available for the majority of these. We have a focus on dementia early onset. Our main research lines include 1) variability in manifestation, 2) early diagnosis, 3) vascular factors and 4) interventions. The Amsterdam Dementia Cohort has been at the basis of the majority of our scientific output illustrating that by employing clinical data to answer research questions, we can benefit the patient care of tomorrow's patients.

\section{ACKNOWLEDGMENTS}

Research of the VUmc Alzheimer center is part of the neurodegeneration research program of the Neuroscience Campus Amsterdam. The VUmc Alzheimer Center is supported by Stichting Alzheimer Nederland and Stichting VUmc fonds. The clinical database structure was developed with funding from Stichting Dioraphte. The new facility of the VUmc Alzheimer Center and the development of the Digital Alzheimer Center have been made possible by a generous grant of 'Innovatiefonds Zorgverzekeraars'.

Authors' disclosures available online (http://www.jalz.com/disclosures/view.php?id=2123).

\section{REFERENCES}

[1] McKhann G, Drachman D, Folstein M, Katzman R, Price D, Stadlan EM (1984) Clinical diagnosis of Alzheimer's disease: Report of the NINCDS-ADRDA Work Group under the auspices of Department of Health and Human Services Task Force on Alzheimer's Disease. Neurology 34, 939-944.

[2] McKhann GM, Knopman DS, Chertkow H, Hyman BT, Jack CR Jr, Kawas CH, Klunk WE, Koroshetz WJ, Manly JJ, Mayeux R, Mohs RC, Morris JC, Rossor MN, Scheltens P, Carillo MC, Thies B, Weintraub S, Phelps $\mathrm{CH}$ (2011) The diagnosis of dementia due to Alzheimer's disease: Recommendations from the National Institute on Aging-Alzheimer's Association workgroups on diagnostic guidelines for Alzheimer's disease. Alzheimers Dement 7, 263-269.

[3] Román GC, Tatemichi TK, Erkinjuntti T, Cummings JL, Masdeu JC, Garcia JH, Amaducci L, Orgogozo JM, Brun A, Hofman A (1993) Vascular dementia: Diagnostic criteria for research studies. Report of the NINDS-AIREN International Workshop. Neurology 43, 250-260.

[4] McKeith IG, Dickson DW, Lowe J, Emre M, O'Brien JT, Feldman H, Cummings J, Duda JE (2005). Diagnosis and management of dementia with Lewy bodies: Third report of the DLB Consortium. Neurology 65, 1863-1872.

[5] Neary D, Snowden JS, Gustafson L, Passant U, Stuss D, Black S, Freedman M, Kertesz A, Robert PH, Albert M, Boone K, Miller BL, Cummings J, Benson DF (1998) Frontotemporal lobar degeneration: A consensus on clinical diagnostic criteria. Neurology 51, 1546-1554.

[6] Rascovsky K, Hodges JR, Knopman D, Mendez MF, Kramer JH, Neuhaus J, van Swieten JC, Seelaar H, Dopper EG, Onyike CU, Hillis AE, Josephs KA, Boeve BF, Kertesz A, Seeley WW, Rankin KP, Johnson JK, Gorno-Tempini ML, Rosen H, Prioleau-Latham CE, Lee A, Kipps CM, Lillo P, Piguet O, Rohrer JD, Rossor MN, Warren JD, Fox NC, Galasko D, Salmon DP, Black SE, Mesulam M, Weintraub S, Dickerson BC, Diehl-Schmid J, Pasquier F, Deramecourt V, Lebert F, Pijnenburg Y, Chow TW, Manes F, Grafman J, Cappa SF, Freedman M, Grossman M, Miller BL (2011) Sensitivity of revised diagnostic criteria for the behavioural variant of frontotemporal dementia. Brain 134, 2456-2477.

[7] Gorno-Tempini ML, Hillis AE, Weintraub S, Kertesz A, Mendez M, Cappa SF, Ogar JM, Rohrer JD, Black S, Boeve BF, Manes F, Dronkers NF, Vandenberghe R, Rascovsky K, Patterson K, Miller BL, Knopman DS, Hodges JR, Mesulam MM, Grossman M (2011) Classification of primary progressive aphasia and its variants. Neurology 76, 1006-1014.

[8] Petersen RC, Smith GE, Waring SC, Ivnik RJ, Tangalos EG, Kokmen E (1999) Mild cognitive impairment: Clinical characterization and outcome. Arch Neurol 56, 303-308.

[9] Albert MS, DeKosky ST, Dickson D, Dubois B, Feldman HH, Fox NC, Gamst A, Holtzman DM, Jagust WJ, Petersen RC, Snyder PJ, Carrillo MC, Thies B, Phelps CH (2011) The diagnosis of mild cognitive impairment due to Alzheimer's disease: Recommendations from the National Institute on Aging-Alzheimer's Association workgroups on diagnostic guidelines for Alzheimer's disease. Alzheimers Dement 7, 270-279.

[10] Cummings JL, Mega MS, Gray K, Rosenberg-Thompson S, Carusi DA, Gornbein J (1994) The Neuropsychiatric Inventory: Comprehensive assessment of psychopathology in dementia. Neurology 44, 2308-2314.

[11] Sheikh JA, Yesavage JA (1986) Geriatric depression scale (GDS): Recent findings and development of a shorter version. In: Clinical Gerontology: A Guide to Assessment and Intervention, Brink TL, ed, Howarth Press, New York.

[12] Gelinas I, Gauthier L, McIntyre M, Gauthier S (1999) Development of a functional measure for persons with Alzheimer's disease: The disability assessment for dementia. Am J Occup Ther 53, 471-481.

[13] Sikkes SA, de Lange-de Klerk ES, Pijnenburg YA, Gillissen F, Romkes R, Knol DL, Uitdehaag BM, Scheltens P (2012) A new informant-based questionnaire for instrumental activities of daily living in dementia. Alzheimers Dement 8, 536543.

[14] Sikkes SA, Knol DL, Pijnenburg YA, de Lange-de Klerk ES, Uitdehaag BM, Scheltens P (2013) Validation of the Amsterdam IADL Questionnaire(c), a new tool to measure 
instrumental activities of daily living in dementia. Neuroepidemiology 41, 35-41.

[15] Hughes CP, Berg L, Danziger WL, Coben LA, Martin RL (1982) A new clinical scale for the staging of dementia. $B r J$ Psychiatry 140, 566-572.

[16] Folstein MF, Folstein SE, McHugh PR (1975) Mini-mental state. A practical method for grading the cognitive state of patients for the clinician. J Psychiatr Res 12, 189-198.

[17] Derix M, Hofstede A, Teunisse S (1992) CAMDEX-N: De nederlandse versie van de Cambridge examination of mental disorders of the elderly. Zwets \& Zeitlinger, Lisse.

[18] Rey A (1964) L'examen clinique en psychologie, Presse de Universitaire de France, Paris.

[19] Saan RJ, Deelman BG (1986) De 15-Woorden Test A en B. (Een voorlopige handleiding, in Dutch).

[20] Lindeboom J, Schmand B, Tulner L, Walstra G, Jonker C (2002) Visual association test to detect early dementia of the Alzheimer type. J Neurol Neurosurg Psychiatry 73, 126133.

[21] Schmand B, Groenink SC, van den Dungen M (2008) [Letter fluency: Psychometric properties and Dutch normative data]. Tijdschr Gerontol Geriatr 39, 64-76.

[22] Snijders J, Luteijn F, van der Ploeg F, Verhage F (1983) Handleiding Groninger intelligentie test. Swets \& Zeitlinger, Lisse.

[23] Warrington EK, James M (1991) The Visual Object and Space Perception Battery. Thames Valley Test Company, Bury St. Edmunds, UK.

[24] Reitan RM (1958) Validity of the Trail Making Test as an indicator of organic brain damage. Percept Mot Skills 8, 271276.

[25] Lindeboom J, Matto D (1994) [Digit series and Knox cubes as concentration tests for elderly subjects]. Tijdschr Gerontol Geriatr 25, 63-68.

[26] Scheltens P, Leys D, Barkhof F, Huglo D, Weinstein HC, Vermersch P, Kuiper M, Steinling M, Wolters EC, Valk J (1992) Atrophy of medial temporal lobes on MRI in "probable" Alzheimer's disease and normal ageing: Diagnostic value and neuropsychological correlates. J Neurol Neurosurg Psychiatry 55, 967-972.

[27] Lehmann M, Koedam EL, Barnes J, Bartlett JW, Ryan NS, Pijnenburg YA, Barkhof F, Wattjes MP, Scheltens P, Fox NC (2012) Posterior cerebral atrophy in the absence of medial temporal lobe atrophy in pathologically-confirmed Alzheimer's disease. Neurobiol Aging 33, 627-633.

[28] Koedam EL, Lehmann M, van der Flier WM, Scheltens P, Pijnenburg YA, Fox N, Barkhof F, Wattjes MP (2011) Visual assessment of posterior atrophy development of a MRI rating scale. Eur Radiol 21, 2618-2625.

[29] Pasquier F, Leys D, Weerts JG, Mounier-Vehier F, Barkhof F, Scheltens P (1996) Inter- and intraobserver reproducibility of cerebral atrophy assessment on MRI scans with hemispheric infarcts. Eur Neurol 36, 268-272.

[30] Fazekas F, Chawluk JB, Alavi A, Hurtig HI, Zimmerman RA (1987) MR signal abnormalities at $1.5 \mathrm{~T}$ in Alzheimer's dementia and normal aging. AJR Am J Roentgenol 149, 351356.

[31] Cordonnier C, van der Flier WM, Sluimer JD, Leys D, Barkhof F, Scheltens P (2006) Prevalence and severity of microbleeds in a memory clinic setting. Neurology 66, 13561360.

[32] Henneman WJ, Sluimer JD, Cordonnier C, Baak MM, Scheltens P, Barkhof F, van der Flier WM (2009) MRI biomarkers of vascular damage and atrophy predicting mortality in a memory clinic population. Stroke 40, 492-498.
[33] Liedorp M, van der Flier WM, Hoogervorst EL, Scheltens P, Stam CJ (2009) Associations between patterns of EEG abnormalities and diagnosis in a large memory clinic cohort. Dement Geriatr Cogn Disord 27, 18-23.

[34] de Waal H, Stam CJ, Blankenstein MA, Pijnenburg YA, Scheltens P, van der Flier WM (2011) EEG abnormalities in early and late onset Alzheimer's disease: Understanding heterogeneity. J Neurol Neurosurg Psychiatry 82, 67-71.

[35] Teunissen CE, Petzold A, Bennett JL, Berven FS, Brundin L, Comabella M, Franciotta D, Frederiksen JL Fleming JO, Furlan R, Hintzen RQ, Hughes SG, Johnson MH, Krasulova E, Kuhle J, Magnone MC, Rajda C, Rejdak K, Schmidt HK, van Pesch V, Waubant E, Wolf C, Giovannoni G, Hemmer B, Tumani H, Deisenhammer F (2009) A consensus protocol for the standardization of cerebrospinal fluid collection and biobanking. Neurology 73, 1914-1922.

[36] Mulder C, Verwey NA, van der Flier WM, Bouwman FH, Kok A, Van Elk EJ, Scheltens P, Blankenstein MA (2010) Amyloid-beta(1-42), total tau, and phosphorylated tau as cerebrospinal fluid biomarkers for the diagnosis of Alzheimer disease. Clin Chem 56, 248-253.

[37] Bateman RJ, Xiong C, Benzinger TL, Fagan AM, Goate A, Fox NC, Marcus DS, Cairns NJ, Xie X, Blazey TM, Holtzman DM, Santacruz A, Buckles V, Oliver A, Moulder K, Aisen PS, Ghetti B, Klunk WE, McDade E, Martins RN, Masters CL, Mayeux R, Ringman JM, Rossor MN, Schofield PR, Sperling RA, Salloway S, Morris JC; Dominantly Inherited Alzheimer Network (2012) Clinical and biomarker changes in dominantly inherited Alzheimer's disease. $N$ Engl J Med 367, 795-804.

[38] Krudop WA, Kerssens CJ, Dols A, Prins ND, Möller C, Schouws S, Barkhof F, van Berckel BN, Teunissen CE, van der Flier WM, Scheltens P, Stek ML, Pijnenburg YA (2013) Building a new paradigm for the early recognition of behavioral variant frontotemporal dementia: Late onset frontal lobe syndrome study. Am J Geriatr Psychiatry. doi: 10.1016/j.jagp.2013.02.002

[39] van Assema DM, Lubberink M, Bauer M, van der Flier WM, Schuit RC, Windhorst AD, Comans EF, Hoetjes NJ, Tolboom N, Langer O, Muller M, Scheltens P, Lammertsma AA, van Berckel BN (2012) Blood-brain barrier P-glycoprotein function in Alzheimer's disease. Brain 135, 181-189.

[40] Binnewijzend MA, Schoonheim MM, Sanz-Arigita E, Wink AM, van der Flier WM, Tolboom N, Adriaanse SM, Damoiseaux JS, Scheltens P, van Berckel BN, Barkhof F (2012) Resting-state fMRI changes in Alzheimer's disease and mild cognitive impairment. Neurobiol Aging 33, 2018-2028.

[41] Adriaanse SM, Sanz-Arigita EJ, Binnewijzend MA, Ossenkoppele R, Tolboom N, van Assema DM, Wink AM, Boellaard R, Yaqub M, Windhorst AD, van der Flier WM, Scheltens P, Lammertsma AA, Rombouts SA, Barkhof F, van Berckel BN (2014) Amyloid and its association with default network integrity in Alzheimer's disease. Hum Brain Mapp 35, 779-791.

[42] Binnewijzend MA, Kuijer JP, Benedictus MR, van der Flier WM, Wink AM, Wattjes MP, van Berckel BN, Scheltens P, Barkhof F (2013) Cerebral blood flow measured with 3D pseudocontinuous arterial spin-labeling MR imaging in Alzheimer disease and mild cognitive impairment: A marker for disease severity. Radiology 267, 221-230.

[43] Hooghiemstra AM, Eggermont LH, Scheltens P, van der Flier WM, Bakker J, de Greef MH, Koppe PA, Scherder EJ (2012) Study protocol: EXERcise and Cognition in Sedentary adults with Early-ONset dementia (EXERCISE-ON). BMC Neurol 12, 75-80. 
[44] Scheltens P, Twisk JW, Blesa R, Scarpini E, von Arnim CA, Bongers A, Harrison J, Swinkels SH, Stam CJ, de WH, Wurtman RJ, Wieggers RL, Vellas B, Kamphuis PJ (2012) Efficacy of Souvenaid in mild Alzheimer's disease: Results from a randomized, controlled trial. J Alzheimers Dis 31, 225-236.

[45] Scheltens P, Kamphuis PJ, Verhey FR, Olde Rikkert MG, Wurtman RJ, Wilkinson D, Twisk JW, Kurz A (2010) Efficacy of a medical food in mild Alzheimer's disease: A randomized, controlled trial. Alzheimers Dement 6, 1-10.e1.

[46] Most EI, Scheltens P, van Someren EJ (2010) Prevention of depression and sleep disturbances in elderly with memoryproblems by activation of the biological clock with light-a randomized clinical trial. Trials 11, 19-23.

[47] Scheltens P, Fox N, Barkhof F, De Carli C (2002) Structural magnetic resonance imaging in the practical assessment of dementia: Beyond exclusion. Lancet Neurol 1, 13-21.

[48] Scheltens P, van de Pol L (2012) Impact commentaries. Atrophy of medial temporal lobes on MRI in "probable" Alzheimer's disease and normal ageing: Diagnostic value and neuropsychological correlates. J Neurol Neurosurg Psychiatry 83, 1038-1040.

[49] Boutet C, Chupin M, Colliot O, Sarazin M, Mutlu G, Drier A, Pellot A, Dormont D, Lehericy S (2012) Is radiological evaluation as good as computer-based volumetry to assess hippocampal atrophy in Alzheimer's disease? Neuroradiology 54, 1321-1330.

[50] Schoonenboom NS, Pijnenburg YA, Mulder C, Rosso SM, Van Elk EJ, van Kamp GJ, van Swieten JC, Scheltens P (2004) Amyloid beta(1-42) and phosphorylated tau in CSF as markers for early-onset Alzheimer disease. Neurology 62 , 1580-1584.

[51] Mattsson N, Zetterberg H, Hansson O, Andreasen N, Parnetti L, Jonsson M, Herukka SK, van der Flier WM, Blankenstein MA, Ewers M, Rich K, Kaiser E, Verbeek M, Tsolaki M, Mulugeta E, Rosén E, Aarsland D, Visser PJ, Schröder J, Marcusson J, de Leon M, Hampel H, Scheltens P, Pirttilä T, Wallin A, Jönhagen ME, Minthon L, Winblad B, Blennow $\mathrm{K}$ (2009) CSF biomarkers and incipient Alzheimer disease in patients with mild cognitive impairment. JAMA 302, 385-393.

[52] Blennow $\mathrm{K}$, Hampel $\mathrm{H}$, CSF markers for incipient Alzheimer's disease (2003) Lancet Neurol 2, 605-613.

[53] Verwey NA, van der Flier WM, Blennow K, Clark C, Sokolow S, De Deyn PP, Galasko D, Hampel H, Hartmann T, Kapaki E, Lannfelt L, Mehta PD, Parnetti L, Petzold A, Pirttila T, Saleh L, Skinningsrud A, Swieten JC, Verbeek MM, Wiltfang J, Younkin S, Scheltens P, Blankenstein MA (2009) A worldwide multicentre comparison of assays for cerebrospinal fluid biomarkers in Alzheimer's disease. Ann Clin Biochem 46, 235-240.

[54] Teunissen CE, Verwey NA, Kester MI, van UK, Blankenstein MA (2010) Standardization of assay procedures for analysis of the CSF biomarkers amyloid beta((1-42)), tau, and phosphorylated tau in Alzheimer's disease: Report of an international workshop. Int J Alzheimers Dis 2010, 1-6.

[55] del CM, Mollenhauer B, Bertolotto A, Engelborghs S, Hampel H, Simonsen AH, Kapaki E, Kruse N (2012) Recommendations to standardize preanalytical confounding factors in Alzheimer's and Parkinson's disease cerebrospinal fluid biomarkers: An update. Biomark Med 6, 419-30.

[56] Mattsson N, Andreasson U, Persson S, Carrillo MC, Collins S, Chalbot S, Cutler N, Dufour-Rainfray D, Fagan AM, Heegaard NH, Robin Hsiung GY, Hyman B, Iqbal K, Lachno DR, Lleó A, Lewczuk P, Molinuevo JL, Parchi P, Regeniter A, Rissman R, Rosenmann H, Sancesario G, Schröder
J, Shaw LM, Teunissen CE, Trojanowski JQ, Vanderstichele $\mathrm{H}$, Vandijck M, Verbeek MM, Zetterberg $\mathrm{H}$, Blennow $\mathrm{K}$, Käser SA; Alzheimer's Association QC Program Work Group (2013) CSF biomarker variability in the Alzheimer's Association quality control program. Alzheimers Dement 9 , 251-261.

[57] Vanderstichele HM, Shaw L, Vandijck M, Jeromin A, Zetterberg H, Blennow K, Teunissen C, Engelborghs S (2013) Alzheimer disease biomarker testing in cerebrospinal fluid: A method to harmonize assay platforms in the absence of an absolute reference standard. Clin Chem 59, 710712 .

[58] Dubois B, Feldman HH, Jacova C, DeKosky ST, BarbergerGateau P, Cummings J, Delacourte A, Galasko D, Gauthier S, Jicha G, Meguro K, O’brien J, Pasquier F, Robert P, Rossor M, Salloway S, Stern Y, Visser PJ, Scheltens P (2007) Research criteria for the diagnosis of Alzheimer's disease: Revising the NINCDS-ADRDA criteria. Lancet Neurol 6, 734-746.

[59] Dubois B, Feldman HH, Jacova C, Cummings JL, DeKosky ST, Barberger-Gateau P, Delacourte A, Frisoni G, Fox NC, Galasko D, Gauthier S, Hampel H, Jicha GA, Meguro K, O'Brien J, Pasquier F, Robert P, Rossor M, Salloway S, Sarazin M, de Souza LC, Stern Y, Visser PJ, Scheltens P (2010). Revising the definition of Alzheimer's disease: A new lexicon. Lancet Neurol 9, 1118-1127.

[60] Tolboom N, Yaqub M, van der Flier WM, Boellaard R, Luurtsema G, Windhorst AD, Barkhof F, Scheltens P, Lammertsma AA, van Berckel BN (2009) Detection of Alzheimer pathology in vivo using both 11C-PIB and 18F-FDDNP PET. $J$ Nucl Med 50, 191-197.

[61] Tolboom N, van der Flier WM, Yaqub M, Boellaard R, Verwey NA, Blankenstein MA, Windhorst AD, Scheltens P, Lammertsma AA, van Berckel BN (2009) Relationship of cerebrospinal fluid markers to $11 \mathrm{C}-\mathrm{PiB}$ and 18F-FDDNP binding. J Nucl Med 50, 1464-1470.

[62] Tolboom N, van der Flier WM, Yaqub M, Koene T, Boellaard R, Windhorst AD, Scheltens P, Lammertsma AA, van Berckel BN (2009) Differential association of [11C]PIB and [18F]FDDNP binding with cognitive impairment. Neurology 73, 2079-2085.

[63] Ossenkoppele R, Tolboom N, Foster-Dingley JC, Adriaanse SF, Boellaard R, Yaqub M, Windhorst AD, Barkhof F, Lammertsma AA, Scheltens P, van der Flier WM, van Berckel BN (2012) Longitudinal imaging of Alzheimer pathology using [11C]PIB, [18F]FDDNP and [18F]FDG PET. Eur J Nucl Med Mol Imaging 39, 990-1000.

[64] Johnson KA, Minoshima S, Bohnen NI, Donohoe KJ, Foster NL, Herscovitch P, Karlawish JH, Rowe CC, Carrillo MC, Hartley DM, Hedrick S, Pappas V, Thies WH (2013) Appropriate use criteria for amyloid PET: A report of the Amyloid Imaging Task Force, the Society of Nuclear Medicine and Molecular Imaging, and the Alzheimer's Association. Alzheimers Dement 9, e-16.

[65] Villemagne VL, Pike KE, Chetelat G, Ellis KA, Mulligan RS, Bourgeat P, Ackermann U, Jones G, RoweC (2011) Longitudinal assessment of Abeta and cognition in aging and Alzheimer disease. Ann Neurol 69, 181-192.

[66] Landau SM, Mintun MA, Joshi AD, Koeppe RA, Petersen RC, Aisen PS, Weiner MW, Jagust WJ (2012) Amyloid deposition, hypometabolism, and longitudinal cognitive decline. Ann Neurol 72, 578-586.

[67] Altmann-Schneider I, Trompet S, de Craen AJ, van Es AC, Jukema JW, Stott DJ, Sattar N, Westendorp RG, van Buchem MA, van der Grond J (2011) Cerebral microbleeds are predictive of mortality in the elderly. Stroke 42, 638-644. 
[68] van der Vlies AE, Goos JD, Barkhof F, Scheltens P, van der Flier WM (2012) Microbleeds do not affect rate of cognitive decline in Alzheimer disease. Neurology 79, 763-769.

[69] Goos JD, Henneman WJ, Sluimer JD, Vrenken H, Sluimer IC, Barkhof F, Blankenstein MA, Scheltens PH, van der Flier WM (2010) Incidence of cerebral microbleeds: A longitudinal study in a memory clinic population. Neurology 74, 19541960.

[70] Cordonnier C, van der Flier WM (2011) Brain microbleeds and Alzheimer's disease: Innocent observation or key player? Brain 134, 335-344.

[71] Sperling RA, Jack CR Jr, Black SE, Frosch MP, Greenberg SM, Hyman BT, Scheltens P, Carrillo MC, Thies W, Bednar
MM, Black RS, Brashear HR, Grundman M, Siemers ER, Feldman HH, Schindler RJ (2011) Amyloid-related imaging abnormalities in amyloid-modifying therapeutic trials: Recommendations from the Alzheimer's Association Research Roundtable Workgroup. Alzheimers Dement 7, 367-385.

[72] Salloway S, Sperling R, Gilman S, Fox NC, Blennow K, Raskind M, Sabbagh M, Honig LS, Doody R, van Dyck CH, Mulnard R, Barakos J, Gregg KM, Liu E, Lieberburg I, Schenk D, Black R, Grundman M; Bapineuzumab 201 Clinical Trial Investigators (2009) A phase 2 multiple ascending dose trial of bapineuzumab in mild to moderate Alzheimer disease. Neurology 73, 2061-2070. 